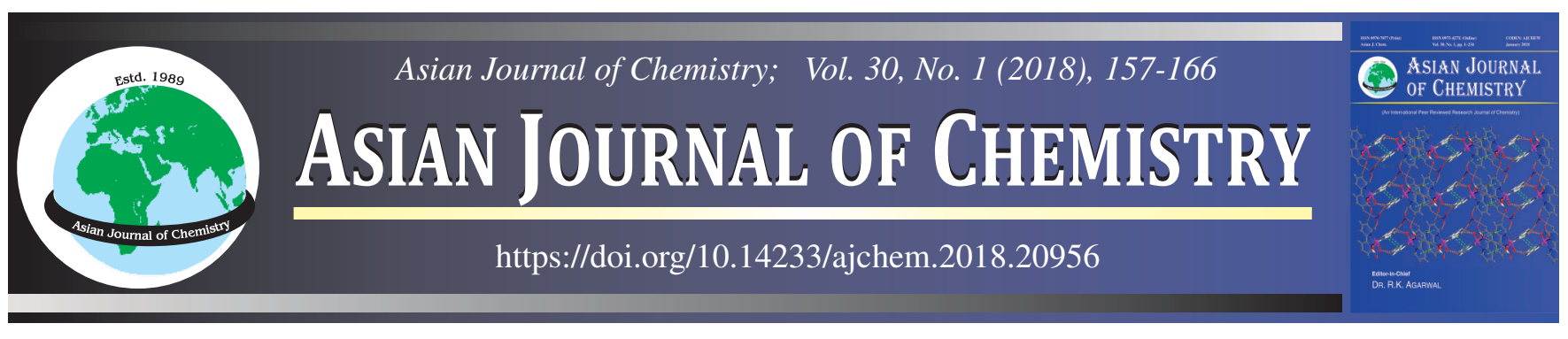

\title{
Study on Molecular Interactions Using Thermodynamic Excess Properties of Binary Mixture Containing Propiophenone with 1-Propanol, 1-Butanol and 1-Pentanol at Temperatures 303.15, 308.15, 313.15 and 318.15 K
}

\section{NAnduri Gayatri Devi ${ }^{1}$, N.V.N.B. Srinivasa RaO ${ }^{2}$, M. Radha Sirija ${ }^{1}$ and D. Ramachandran ${ }^{1, *}$}

${ }^{1}$ Department of Chemistry, Acharya Nagarjuna University, Guntur-522 510, India

${ }^{2}$ Department of Chemistry, Government Degree College, Tadepalligudem-534166, India

*Corresponding author: E-mail: dittakavirc17@gmail.com

\begin{abstract}
The current study works out on densities ' $\rho$ ', ultrasonic speeds of sound 'u' of binary mixtures of propiophenone with $n$-alcohols $e$.g., 1 propanol, 1-butanol and 1-pentanol measured over the entire composition range at 303.15 to $318.15 \mathrm{~K}$ and at atmospheric pressure 0.1 MPa. The worked out experimental data has been used to calculate various thermodynamic excess parameters like excess molar volume $\left(\mathrm{V}^{\mathrm{E}}\right)$, excess ultrasonic velocity $\left(\mathrm{U}^{\mathrm{E}}\right)$, excess acoustic impedance $\left(\mathrm{Z}^{\mathrm{E}}\right)$, excess intermolecular free-length $\left(\mathrm{L}_{\mathrm{f}}^{\mathrm{E}}\right)$, deviation in isentropic compressibility $(\Delta \mathrm{Ks})$, deviation in acoustic impedance $(\Delta \mathrm{Z})$ and the computed results were fitted with the Redlich Kister equation to estimate the binary coefficients and standard deviation between experimental and calculated data. Partial molar volume of the binary mixtures was calculated to understand more of the intermolecular reactions in the above binary mixtures.
\end{abstract}

Keywords: Excess molecular volume, Partial molar volume, Deviation in compressibility, Impedance, Ultrasonic sound.

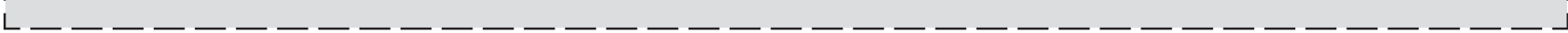

\section{INTRODUCTION}

Study of thermo-physical properties of liquid mixtures has more impact on academic and industrial importance. Thermodynamic properties of binary mixtures are essential to know the behaviour and type of inter molecular interactions between the components of the liquid mixtures at different compositions and temperatures. The excess property study has been used for the design of equipment in heat transfer, fluid mechanics, process calculation and process control. The investigations have been carried out on phenols [1-3] and alcohols [4,5] and more study on phenones [6-12] and on methyl acetate [13] has been reported. Literature survey shows that no work has been reported on these mixtures at such temperatures. Propiophenone with alkanol mixtures are having various applications in chemical industries. Propiophenone is widely used component in perfumes industries. It is used in the synthesis of ketoamphetamines such as cathinone and methcathinone. It is also used as a volatile low toxicity solvent in glues, paints and nail polish removers [13]. The effect of temperature and chain length on 1-alcohols when mixed with propiophenone may induce changes in sign and magnitude of excess thermodynamic and transport properties [14]. Hence, the current study on these binary mixtures has been carried out at $303.15,308.15,313.15$ and $318.15 \mathrm{~K}$ to understand the behaviour of intermolecular interactions.

Alcohols play an important role in many chemical reactions due to the ability to undergo self-association with manifold internal structures and are in wide use in industry and science as reagents, solvents and fuels and attract great attention as useful solvents in the green technology [15]. The effect of molecular size, shape, chain length and degree of molecular association of normal alkanols and associated alkanols on the volumetric, viscosity and acoustic properties of binary mixtures containing acetronitrile, dimethyl sulfoxide, ethyl acetate and benzonitrile have been studied earlier [16-26].

This research paper presents the data on densities, ultrasonic velocity of binary liquid mixtures of propiophenone (PPH) with 1-propanol, 1-butanol and 1-pentanol at 303.15, $308.15,313.15$ and $318.15 \mathrm{~K}$. The experimental values of density, speed of sound are used to calculate various acoustical parameters like acoustic impedance (Z), isentropic compressibility $(\mathrm{Ks})$, Inter molecular free-length $\left(\mathrm{L}_{\mathrm{f}}\right)$. Various excess properties like excess ultrasonic velocity $\left(\mathrm{U}^{\mathrm{E}}\right)$, excess acoustic impedance $\left(\mathrm{Z}^{\mathrm{E}}\right)$, deviation in isentropic compressibility $\left(\Delta \mathrm{K}_{\mathrm{S}}\right)$ and excess inter molecular free-length $\left(\mathrm{L}_{\mathrm{f}}^{\mathrm{E}}\right)$ were calculated. Variations in excess properties of these binary mixtures at all four temperatures reflect the strong interactions between the 
unlike molecules. Calculated excess properties' values were fitted to the Redlich Kister equation to estimate the standard deviations between the experimental and calculated values. A partial molar property is a thermodynamic quantity which indicates how an extensive property of a solution or mixture varies with changes in the molar composition of the mixture at constant temperature and pressure. An extended analysis on partial molar volume is also calculated for the above mixtures at all four temperatures.

\section{EXPERIMENTAL}

Propiophenone (purity $>98 \%$ ), 1-propanol (purity $>99$ $\%$ ), 1-butanol (purity $>99 \%$ ) and 1-pentanol (purity $>99 \%$ ) were purchased from S.D. Fine chemicals Ltd, India and used as such.

Estimated purities of the liquid samples are greater than $99 \%$ and water content found less than 0.003 mass \%. Mixtures were prepared by mixing weighed amounts of the pure liquids adopting the method of closed system by using Mettler Toledo (ME204) balance with the precision of $\pm 0.1 \mathrm{mg}$. Mixtures were allowed to stand for some time before every measurement so as to avoid air bubbles. The purities of the liquids were checked by comparing the values of densities and ultrasonic velocities with literature data (Table-1).

Proper care was taken to avoid any evaporation loss while doing the experiment. The densities of liquids and their mixtures were measured using bi-capillary pycnometer having a capillary diameter of $0.85 \mathrm{~mm}$, which was calibrated using double distilled water. The necessary buoyancy corrections were applied. The density $(\rho)$ values were reproducible within $\pm 0.2 \mathrm{Kg} \mathrm{m}^{-3}$. The ultrasonic velocity (u) measurements were measured by a single frequency $(2 \mathrm{MHz})$ variable path interferometer with an error of $\pm 0.0001 \%$ ultrasonic interferometer model F-05
(S. No. 1415342) Mittal Enterprises, New Delhi. The mole fraction of each mixture measured with the masses of the components.

\section{RESULTS AND DISCUSSION}

The experimental values of ultrasonic velocity and density of binary mixtures at $303.15,308.15,313.15$ and $318.15 \mathrm{~K}$ with respective mole fractions $\left(\mathrm{x}_{1}\right)$ are reported in Table-2.

The density values were used to calculate excess molar volumes $\mathrm{V}^{\mathrm{E}}$ using the following equation:

$$
V^{E}=\frac{x_{1} M_{1}+x_{2} M_{2}}{\rho_{m}}-\left\{\frac{x_{1} M_{1}}{\rho_{1}}+\frac{x_{2} M_{2}}{\rho_{2}}\right\}
$$

$\mathrm{V}^{\mathrm{E}}\left(\mathrm{cm}^{3} \mathrm{~mol}^{-1}\right)$ is excess molar volume, where $\rho_{\mathrm{m}}$ is the density of the mixture and $\left(\mathrm{x}_{1}, \mathrm{M}_{1}, \rho_{1}\right)$ and $\left(\mathrm{x}_{2}, \mathrm{M}_{2}, \rho_{2}\right)$ are the molefraction, the molecular weight and the density of pure components 1 and 2, respectively.

The isentropic compressibility $\left(\mathrm{K}_{\mathrm{S}}\right)$ was calculated using the Laplace relation:

$$
\mathrm{K}_{\mathrm{S}}=\mathrm{U}^{-2} \rho^{-1}
$$

where $\mathrm{U}$ is the ultrasonic velocity and $\rho$ the density.

The deviation in isentropic compressibility $\left(\Delta \mathrm{K}_{\mathrm{S}}\right)$ obtained using the relation:

$$
\Delta \mathrm{K}_{\mathrm{S}}\left(\mathrm{TPa}^{-1}\right)=\mathrm{K}_{\mathrm{S}}{ }^{12}-\phi_{1} \mathrm{~K}_{\mathrm{S}^{1}}-\phi_{2} \mathrm{~K}_{\mathrm{S}}^{2}
$$

where $\mathrm{K}_{\mathrm{S}^{12}}$ is the experimental isentropic compressibility of the mixture and $\phi_{1}, \phi_{2}$ and $K_{S^{1}}, K_{S^{2}}$ are the volume fractions and isentropic compressibility, respectively, of the pure components.

The $\phi_{\mathrm{i}}$ is the ideal state volume fraction and is defined by the relation:

$$
\phi_{\mathrm{i}}=\frac{\mathrm{x}_{\mathrm{i}} \mathrm{V}_{\mathrm{i}}}{\sum_{\mathrm{i}=1}^{2} \mathrm{x}_{\mathrm{i}} \mathrm{V}_{\mathrm{i}}}
$$

\begin{tabular}{cccc|cc}
\multicolumn{6}{c}{ PHYSICAL PROPERTIES OF PURE COMPONENTS; COMPARISON OF EXPERIMENTAL VALUES OF DENSITIES, } \\
ULTRASONIC VELOCITY AND VISCOSITIES OF PURE LIQUIDS WITH THE CORRESPONDING \\
LITERATURE VALUES AT VARIOUS TEMPERTURES
\end{tabular}

(a): [Ref. 27], (b): [Ref. 28], (c): [Ref. 29], (d): [Ref. 30], (e): [Ref. 31], (f): [Ref. 32], (g): [Ref. 33], (h): [Ref. 34], (i): [Ref. 35], (j): [Ref. 36], (k): [Ref. 37], (l): [Ref. 38], (m): [Ref. 39], (n): [Ref. 40], (o): [Ref. 41], (p): [Ref. 42], (q): [Ref. 43], (r): [Ref. 44], (s): [Ref. 45], (t): [Ref. 46], (u): [Ref. 47]. 


\begin{tabular}{|c|c|c|c|c|c|c|c|c|}
\hline \multirow{3}{*}{$\mathrm{x}_{1}$} & \multicolumn{7}{|c|}{$\begin{array}{c}\text { TABLE-2 } \\
\text { EXPERIMENTAL VALUES OF BINARY MIXTURES OF PROPIOPHENONE WITH } \\
\text { 1-PROPANOL, 1-BUTANOL AND 1-PENTANOL AT 303.15, 308.15, 313.15 AND 318.15 K }\end{array}$} & \\
\hline & \multicolumn{2}{|c|}{$303.15 \mathrm{~K}$} & \multicolumn{2}{|c|}{$308.15 \mathrm{~K}$} & \multicolumn{2}{|c|}{$313.15 \mathrm{~K}$} & \multicolumn{2}{|c|}{$318.15 \mathrm{~K}$} \\
\hline & $\rho\left(\mathrm{g} \mathrm{cm}^{-3}\right)$ & $\mathrm{U}\left(\mathrm{m} \mathrm{s}^{-1}\right)$ & $\rho\left(\mathrm{g} \mathrm{cm}^{-3}\right)$ & $\mathrm{U}\left(\mathrm{m} \mathrm{s}^{-1}\right)$ & $\rho\left(\mathrm{g} \mathrm{cm}^{-3}\right)$ & $\mathrm{U}\left(\mathrm{m} \mathrm{s}^{-1}\right)$ & $\rho\left(\mathrm{g} \mathrm{cm}^{-3}\right)$ & $\mathrm{U}\left(\mathrm{m} \mathrm{s}^{-1}\right)$ \\
\hline \multicolumn{9}{|c|}{ Propiophenone + 1-propanol } \\
\hline 0 & 0.7953 & 1197.90 & 0.7914 & 1166.28 & 0.7873 & 1135.71 & 0.7834 & 1109.83 \\
\hline 0.0588 & 0.8179 & 1213.06 & 0.8146 & 1182.45 & 0.8111 & 1152.50 & 0.8083 & 1126.88 \\
\hline 0.1233 & 0.8404 & 1229.69 & 0.8372 & 1199.90 & 0.8338 & 1170.51 & 0.8311 & 1145.07 \\
\hline 0.1943 & 0.8627 & 1247.77 & 0.8596 & 1218.82 & 0.8562 & 1189.99 & 0.8536 & 1164.73 \\
\hline 0.2728 & 0.8846 & 1267.53 & 0.8815 & 1239.52 & 0.8783 & 1211.27 & 0.8756 & 1186.20 \\
\hline 0.3601 & 0.9060 & 1289.35 & 0.9030 & 1262.39 & 0.8998 & 1234.77 & 0.8972 & 1209.80 \\
\hline 0.4577 & 0.9267 & 1313.58 & 0.9237 & 1287.81 & 0.9207 & 1260.89 & 0.9181 & 1236.11 \\
\hline 0.5676 & 0.9466 & 1340.65 & 0.9437 & 1316.20 & 0.9407 & 1290.10 & 0.9383 & 1265.60 \\
\hline 0.6924 & 0.9657 & 1371.22 & 0.9629 & 1348.28 & 0.9601 & 1323.16 & 0.9577 & 1298.90 \\
\hline 0.8351 & 0.9845 & 1406.10 & 0.9819 & 1384.91 & 0.9792 & 1360.80 & 0.9769 & 1336.86 \\
\hline 1.0000 & 1.0045 & 1446.41 & 1.0015 & 1427.04 & 0.9985 & 1403.95 & 0.9955 & 1380.00 \\
\hline \multicolumn{9}{|c|}{ Propiophenone + 1-butanol } \\
\hline 0 & 0.8022 & 1230.11 & 0.7982 & 1215.87 & 0.7943 & 1201.80 & 0.7904 & 1188.31 \\
\hline 0.0710 & 0.8236 & 1246.38 & 0.8199 & 1232.06 & 0.8164 & 1217.62 & 0.8128 & 1203.66 \\
\hline 0.1468 & 0.8449 & 1263.48 & 0.8415 & 1248.74 & 0.8382 & 1233.87 & 0.8348 & 1219.12 \\
\hline 0.2278 & 0.8662 & 1281.47 & 0.8629 & 1266.36 & 0.8596 & 1250.57 & 0.8563 & 1235.17 \\
\hline 0.3145 & 0.8872 & 1300.48 & 0.8839 & 1284.91 & 0.8807 & 1268.45 & 0.8774 & 1252.02 \\
\hline 0.4077 & 0.9077 & 1320.73 & 0.9045 & 1304.68 & 0.9013 & 1287.34 & 0.8981 & 1269.89 \\
\hline 0.5080 & 0.9276 & 1342.34 & 0.9245 & 1325.82 & 0.9213 & 1307.57 & 0.9182 & 1289.16 \\
\hline 0.6163 & 0.9468 & 1365.59 & 0.9438 & 1348.55 & 0.9408 & 1329.37 & 0.9378 & 1309.94 \\
\hline 0.7336 & 0.9656 & 1390.59 & 0.9628 & 1373.04 & 0.9600 & 1352.86 & 0.9571 & 1332.25 \\
\hline 0.8610 & 0.9845 & 1417.52 & 0.9817 & 1399.35 & 0.9791 & 1377.91 & 0.9763 & 1355.92 \\
\hline 1.0000 & 1.0045 & 1446.41 & 1.0015 & 1427.04 & 0.9985 & 1403.95 & 0.9955 & 1380.00 \\
\hline \multicolumn{9}{|c|}{ Propiophenone + 1-pentanol } \\
\hline 0 & 0.8076 & 1264.79 & 0.8040 & 1243.60 & 0.8002 & 1220.23 & 0.7960 & 1196.24 \\
\hline 0.0836 & 0.8279 & 1280.92 & 0.8246 & 1260.49 & 0.8212 & 1237.59 & 0.8174 & 1214.11 \\
\hline 0.1703 & 0.8484 & 1297.42 & 0.8453 & 1277.15 & 0.8420 & 1254.27 & 0.8384 & 1230.79 \\
\hline 0.2602 & 0.8689 & 1314.29 & 0.8658 & 1294.18 & 0.8626 & 1271.33 & 0.8591 & 1247.85 \\
\hline 0.3537 & 0.8891 & 1331.59 & 0.8860 & 1311.65 & 0.8829 & 1288.83 & 0.8794 & 1265.35 \\
\hline 0.4508 & 0.9090 & 1349.37 & 0.9060 & 1329.60 & 0.9028 & 1306.81 & 0.8994 & 1283.34 \\
\hline 0.5518 & 0.9285 & 1367.71 & 0.9255 & 1348.12 & 0.9224 & 1325.36 & 0.9191 & 1301.89 \\
\hline 0.6570 & 0.9474 & 1386.53 & 0.9446 & 1367.13 & 0.9416 & 1344.40 & 0.9385 & 1320.93 \\
\hline 0.7665 & 0.9662 & 1405.87 & 0.9634 & 1386.67 & 0.9606 & 1363.97 & 0.9577 & 1340.51 \\
\hline 0.8808 & 0.9850 & 1425.73 & 0.9823 & 1406.74 & 0.9795 & 1384.07 & 0.9767 & 1360.62 \\
\hline 1.0000 & 1.0045 & 1446.41 & 1.0015 & 1427.04 & 0.9985 & 1403.95 & 0.9955 & 1380.00 \\
\hline
\end{tabular}

Deviation in ultrasonic speed of sound $(\Delta \mathrm{U})$ calculated by using the following relation:

$$
\Delta_{\mathrm{U}}=\mathrm{U}-\left(\mathrm{x}_{1} \mathrm{U}_{1}+\mathrm{x}_{2} \mathrm{U}_{2}\right)
$$

where $\mathrm{U}$ is the experimental ultrasonic speed for the mixture, $\mathrm{x}_{1}, \mathrm{x}_{2}, \mathrm{U}_{1}, \mathrm{U}_{2}$ are the mole fractions and ultrasonic speed of the pure components 1 and 2, respectively.

In an attempt to explore the nature of the interactions, various thermodynamic parameters like intermolecular free length $\left(\mathrm{L}_{\mathrm{f}}\right)$ [48]; acoustic impedance $(\mathrm{Z})$ [49]; of the binary mixtures have been calculated using the following equations:

$$
\mathrm{L}_{\mathrm{f}}=\mathrm{K} \rho^{\frac{1}{2}}
$$

where $L_{f}$ is the intermolecular free length, $K$ is the isentropic compressibility and $\rho$ is the density.

Acoustic impedance calculated by using the relation:

$$
\mathrm{Z}=\mathrm{U} \rho
$$

where $\mathrm{Z}$ is the acoustic impedance, $\mathrm{U}$ is the ultrasonic speed of sound and $\rho$ is the density.

Excess molar free length $\left(\mathrm{L}_{\mathrm{f}}^{\mathrm{E}}\right)$ calculated by using the relation:

$$
\mathrm{L}_{\mathrm{f}}^{\mathrm{E}}=\mathrm{L}_{\mathrm{f}}-\left(\mathrm{x}_{1} \mathrm{~L}_{\mathrm{f} 1}+\mathrm{x}_{2} \mathrm{~L}_{\mathrm{f} 2}\right)
$$

where $\mathrm{L}_{f}^{\mathrm{E}}$ is excess molar free length, $\mathrm{L}_{f}$ is intermolecular free length of the mixture, $\mathrm{x}_{1}, \mathrm{x}_{2}, \mathrm{~L}_{\mathrm{f} 1}$ and $\mathrm{L}_{\mathrm{f} 2}$ are the mole fraction and intermolecular free length for pure components 1 and 2 respectively.

Deviation in acoustic impedance calculated by using the relation:

$$
\Delta \mathrm{Z}=\mathrm{Z}-\left(\mathrm{x}_{1} \mathrm{Z}_{1}+\mathrm{x}_{2} \mathrm{Z}_{2}\right)
$$

where $\Delta \mathrm{Z}$ is the deviation in acoustic impedance, $\mathrm{Z}$ is the acoustic impedance of the mixture, $\mathrm{x}_{1}, \mathrm{x}_{2}, \mathrm{Z}_{1}, \mathrm{Z}_{2}$ are the mole fraction and acoustic impedances of pure components 1 and 2 respectively.

The non-linear variation is a deviation from ideal behaviour which suggests the presence of intermolecular interactions between the component molecules of the mixtures, however the strength of interaction is well reflected in the excess parameters like excess molar volume $\left(\mathrm{V}^{\mathrm{E}}\right)$, partial molar volume $(\mathrm{PMV})$ and deviation in isentropic compressibility $(\Delta \mathrm{Ks})$, deviation in ultrasonic speed of sound $(\Delta \mathrm{U})$, deviation in 
acoustic impedance $(\Delta \mathrm{Z})$, excess intermolecular free length $\left(\mathrm{L}_{\mathrm{f}}^{\mathrm{E}}\right)$, etc., as these parameters are found to be more sensitive towards intermolecular interactions in the liquid mixtures [50].

From the thermodynamic point of view - the ultrasonic velocity, isentropic compressibility, deviation in isentropic compressibility, free length along with the other data like excess molar volume, are strongly affected by the changes of concentration and temperature, besides the type of bonding present between the molecules of the constituent liquids.
Hydrogen bonding causes considerable influence on these parameters, because of the fact that specific interactions between the molecules are controlled mainly by hydrogen bond that binds the molecules together. Computed values of the parameters analyzed $\left(\mathrm{V}^{\mathrm{E}}, \Delta \mathrm{Ks}, \Delta \mathrm{U}, \Delta \mathrm{Z}\right.$ and $\left.\mathrm{L}_{\mathrm{f}}^{\mathrm{E}}\right)$, are given in Table-3 at $303.15,308.15,313.15$ and $318.15 \mathrm{~K}$ for the binary mixtures of propio-phenone with 1-propanol, 1-butanol and 1-pentanol.

Excess molar volume $\left(V_{m}{ }^{\mathbf{E}}\right)$ : Fig. 1 represents the variation of $\mathrm{V}^{\mathrm{E}}$ with the mole fraction $\mathrm{X}_{1}$ of propiophenone with

TABLE-3

VALUES OF EXCESS MOLAR VOLUME $\left(\mathrm{V}_{\mathrm{m}}{ }^{\mathrm{E}}\right)$, ULTRASONIC VELOCITY $(\Delta \mathrm{U})$, EXCESS ISENTROPIC COMPRESSIBILITY ( $\triangle$ Ks), EXCESS ACOUSTIC IMPEDANCE $(\Delta z)$ AND EXCESS INTERMOLECULAR FREE-LENGTH $\left(L_{f}^{E}\right)$ FOR THE BINARY LIQUIDMIXTURES OF PROPIOPHENONE WITH 1-PROPANOL, 1-BUTANOL AND 1-PENTANOL AT DIFFERENT TEMPERATURE

\begin{tabular}{|c|c|c|c|c|c|c|c|c|c|c|c|}
\hline $\mathrm{x}_{1}$ & $\begin{array}{l}\mathrm{V}^{\mathrm{E}}\left(\mathrm{cm}^{3}\right. \\
\left.\mathrm{mol}^{-1}\right)\end{array}$ & $\begin{array}{c}\Delta \mathrm{Ks} \\
\left(\mathrm{pa}^{-1}\right)\end{array}$ & $\begin{array}{c}\Delta \mathrm{U} \\
\left(\mathrm{m} \mathrm{s}^{-1}\right)\end{array}$ & $\begin{array}{c}\Delta \mathrm{Z}\left(10^{-3} /\right. \\
\left.\mathrm{Kg} \mathrm{m}^{-2} \mathrm{~s}^{-1}\right)\end{array}$ & $\begin{array}{c}\mathrm{L}_{\mathrm{f}}^{\mathrm{E}}(10- \\
10 \mathrm{~m}) \\
\end{array}$ & $\mathrm{x}_{1}$ & $\begin{array}{l}\mathrm{V}^{\mathrm{E}}\left(\mathrm{cm}^{3}\right. \\
\left.\mathrm{mol}^{-1}\right)\end{array}$ & $\begin{array}{c}\Delta \mathrm{Ks} \\
\left(\mathrm{pa}^{-1}\right)\end{array}$ & $\begin{array}{c}\Delta \mathrm{U} \\
\left(\mathrm{m} \mathrm{s}^{-1}\right)\end{array}$ & $\begin{array}{c}\Delta \mathrm{Z}\left(10^{-3} /\right. \\
\left.\mathrm{Kg} \mathrm{m}^{-2} \mathrm{~s}^{-1}\right)\end{array}$ & $\begin{array}{c}\mathrm{L}_{\mathrm{f}}^{\mathrm{E}}(10- \\
10 \mathrm{~m}) \\
\end{array}$ \\
\hline \multicolumn{6}{|c|}{ Propiophenone + 1-propanol at $303.15 \mathrm{~K}$} & \multicolumn{6}{|c|}{ Propiophenone + 1-propanol at $308.15 \mathrm{~K}$} \\
\hline 0.0000 & 0.0000 & 0.0000 & 0.0000 & 0.0000 & 0.0000 & 0.0000 & 0.0000 & 0.0000 & 0.0000 & 0.0000 & 0.0000 \\
\hline 0.0588 & -0.1702 & -2.1795 & 0.5366 & 0.0100 & -0.6833 & 0.0588 & -0.2289 & -2.5187 & 0.8284 & 0.0105 & -0.7896 \\
\hline 0.1233 & -0.3384 & -3.9961 & 1.1423 & 0.0190 & -1.2528 & 0.1233 & -0.3974 & -4.5235 & 1.4707 & 0.0191 & -1.4181 \\
\hline 0.1943 & -0.4888 & -5.3922 & 1.5846 & 0.0265 & -1.6905 & 0.1943 & -0.5539 & -6.0604 & 1.8840 & 0.0263 & -1.8999 \\
\hline 0.2728 & -0.6129 & -6.3432 & 1.8337 & 0.0322 & -1.9886 & 0.2728 & -0.6730 & -7.0978 & 2.1138 & 0.0316 & -2.2252 \\
\hline 0.3601 & -0.6831 & -6.8156 & 1.9667 & 0.0354 & -2.1367 & 0.3601 & -0.7431 & -7.6117 & 2.2235 & 0.0347 & -2.3863 \\
\hline 0.4577 & -0.6784 & -6.7599 & 1.9337 & 0.0357 & -2.1192 & 0.4577 & -0.7383 & -7.5454 & 2.1867 & 0.0349 & -2.3655 \\
\hline 0.5676 & -0.5789 & -6.1167 & 1.6812 & 0.0324 & -1.9176 & 0.5676 & -0.6389 & -6.8282 & 1.9024 & 0.0317 & -2.1406 \\
\hline 0.6924 & -0.3846 & -4.8280 & 1.2605 & 0.0251 & -1.5136 & 0.6924 & -0.4446 & -5.3980 & 1.4619 & 0.0248 & -1.6923 \\
\hline 0.8351 & -0.1348 & -2.8147 & 0.6655 & 0.0139 & -0.8824 & 0.8351 & -0.1947 & -3.1654 & 0.8740 & 0.0141 & -0.9924 \\
\hline 1.0000 & 0.0000 & 0.0000 & 0.0000 & 0.0000 & 0.0000 & 1.0000 & 0.0000 & 0.0000 & 0.0000 & 0.0000 & 0.0000 \\
\hline \multicolumn{6}{|c|}{ Propiophenone + 1-butanol at $303.15 \mathrm{~K}$} & \multicolumn{6}{|c|}{ Propiophenone + 1-butanol at $308.15 \mathrm{~K}$} \\
\hline 0.0000 & 0.0000 & 0.0000 & 0.0000 & 0.0000 & 0.0000 & 0.0000 & 0.0000 & 0.0000 & 0.0000 & 0.0000 & 0.0000 \\
\hline 0.0710 & -0.1375 & -1.7424 & 0.9021 & 0.0065 & -0.5462 & 0.0710 & -0.1774 & -1.8616 & 1.1873 & 0.0071 & -0.5836 \\
\hline 0.1468 & -0.2800 & -3.1309 & 1.6084 & 0.0123 & -0.9815 & 0.1468 & -0.3401 & -3.2954 & 1.8631 & 0.0130 & -1.0331 \\
\hline 0.2278 & -0.4141 & -4.1526 & 2.0846 & 0.0170 & -1.3018 & 0.2278 & -0.4769 & -4.3469 & 2.3897 & 0.0178 & -1.3627 \\
\hline 0.3145 & -0.5105 & -4.7884 & 2.3337 & 0.0204 & -1.5012 & 0.3145 & -0.5696 & -4.9892 & 2.6188 & 0.0210 & -1.5641 \\
\hline 0.4077 & -0.5520 & -5.0351 & 2.4350 & 0.0220 & -1.5785 & 0.4077 & -0.6039 & -5.2327 & 2.7186 & 0.0226 & -1.6404 \\
\hline 0.5080 & -0.5198 & -4.8746 & 2.3525 & 0.0216 & -1.5282 & 0.5080 & -0.5695 & -5.0656 & 2.6787 & 0.0222 & -1.5881 \\
\hline 0.6163 & -0.4020 & -4.3012 & 2.1812 & 0.0189 & -1.3484 & 0.6163 & -0.4529 & -4.4750 & 2.5390 & 0.0196 & -1.4029 \\
\hline 0.7336 & -0.2209 & -3.3008 & 1.8103 & 0.0141 & -1.0348 & 0.7336 & -0.2800 & -3.4538 & 2.2605 & 0.0150 & -1.0828 \\
\hline 0.8610 & -0.0409 & -1.8703 & 1.1776 & 0.0074 & -0.5863 & 0.8610 & -0.0917 & -1.9780 & 1.6612 & 0.0084 & -0.6201 \\
\hline 1.0000 & 0.0000 & 0.0000 & 0.0000 & 0.0000 & 0.0000 & 1.0000 & 0.0000 & 0.0000 & 0.0000 & 0.0000 & 0.0000 \\
\hline \multicolumn{6}{|c|}{ Propiophenone +1-pentanol at $303.15 \mathrm{~K}$} & \multicolumn{6}{|c|}{ Propiophenone +1-pentanol at $308.15 \mathrm{~K}$} \\
\hline 0.0000 & 0.0000 & 0.0000 & 0.0000 & 0.0000 & 0.0000 & 0.0000 & 0.0000 & 0.0000 & 0.0000 & 0.0000 & 0.0000 \\
\hline 0.0836 & -0.0700 & -1.2954 & 0.9582 & 0.0030 & -0.4061 & 0.0836 & -0.1145 & -1.4773 & 1.5582 & 0.0037 & -0.4631 \\
\hline 0.1703 & -0.1684 & -2.3041 & 1.7139 & 0.0058 & -0.7223 & 0.1703 & -0.2285 & -2.5497 & 2.3139 & 0.0066 & -0.7993 \\
\hline 0.2602 & -0.2660 & -3.0150 & 2.2405 & 0.0082 & -0.9452 & 0.2602 & -0.3275 & -3.2962 & 2.8405 & 0.0089 & -1.0334 \\
\hline 0.3537 & -0.3358 & -3.4270 & 2.5694 & 0.0099 & -1.0744 & 0.3537 & -0.3880 & -3.7204 & 3.1694 & 0.0105 & -1.1663 \\
\hline 0.4508 & -0.3611 & -3.5435 & 2.7105 & 0.0106 & -1.1109 & 0.4508 & -0.4095 & -3.8357 & 3.3105 & 0.0112 & -1.2025 \\
\hline 0.5518 & -0.3312 & -3.3726 & 2.6987 & 0.0103 & -1.0573 & 0.5518 & -0.3748 & -3.6469 & 3.2987 & 0.0109 & -1.1433 \\
\hline 0.6570 & -0.2400 & -2.9111 & 2.4201 & 0.0087 & -0.9126 & 0.6570 & -0.2930 & -3.1578 & 3.0202 & 0.0095 & -0.9900 \\
\hline 0.7665 & -0.1184 & -2.1792 & 1.8631 & 0.0061 & -0.6832 & 0.7665 & -0.1790 & -2.3816 & 2.4631 & 0.0070 & -0.7466 \\
\hline 0.8808 & -0.0112 & -1.1943 & 0.9764 & 0.0028 & -0.3744 & 0.8808 & -0.0600 & -1.3292 & 1.5764 & 0.0038 & -0.4167 \\
\hline 1.0000 & 0.0000 & 0.0000 & 0.0000 & 0.0000 & 0.0000 & 1.0000 & 0.0000 & 0.0000 & 0.0000 & 0.0000 & 0.0000 \\
\hline \multicolumn{6}{|c|}{ Propiophenone + 1-propanol at $313.15 \mathrm{~K}$} & \multicolumn{6}{|c|}{ Propiophenone + 1-propanol at $318.15 \mathrm{~K}$} \\
\hline 0.0000 & 0.0000 & 0.0000 & 0.0000 & 0.0000 & 0.0000 & 0.0000 & 0.0000 & 0.0000 & 0.0000 & 0.0000 & 0.0000 \\
\hline 0.0588 & -0.2845 & -2.8536 & 1.0076 & 0.0108 & -0.8946 & 0.0588 & -0.3900 & -3.2184 & 1.1568 & 0.0118 & -1.0090 \\
\hline 0.1233 & -0.4591 & -5.0598 & 1.7139 & 0.0192 & -1.5862 & 0.1233 & -0.5690 & -5.5894 & 1.9230 & 0.0200 & -1.7523 \\
\hline 0.1943 & -0.6148 & -6.7402 & 2.1623 & 0.0261 & -2.1130 & 0.1943 & -0.7268 & -7.3880 & 2.4097 & 0.0267 & -2.3161 \\
\hline 0.2728 & -0.7334 & -7.8689 & 2.3897 & 0.0312 & -2.4669 & 0.2728 & -0.8449 & -8.5903 & 2.6682 & 0.0317 & -2.6931 \\
\hline 0.3601 & -0.8031 & -8.4214 & 2.4696 & 0.0341 & -2.6401 & 0.3601 & -0.9131 & -9.1616 & 2.6882 & 0.0344 & -2.8722 \\
\hline 0.4577 & -0.7983 & -8.3394 & 2.4002 & 0.0344 & -2.6144 & 0.4577 & -0.9083 & -9.0619 & 2.6188 & 0.0346 & -2.8409 \\
\hline 0.5676 & -0.6989 & -7.5493 & 2.1236 & 0.0313 & -2.3667 & 0.5676 & -0.8089 & -8.2097 & 2.4097 & 0.0318 & -2.5737 \\
\hline 0.6924 & -0.5046 & -5.9801 & 1.7234 & 0.0247 & -1.8748 & 0.6924 & -0.6146 & -6.5133 & 2.0124 & 0.0253 & -2.0419 \\
\hline 0.8351 & -0.2557 & -3.5209 & 1.0825 & 0.0144 & -1.1038 & 0.8351 & -0.3666 & -3.8642 & 1.4154 & 0.0154 & -1.2114 \\
\hline 1.0000 & 0.0000 & 0.0000 & 0.0000 & 0.0000 & 0.0000 & 1.0000 & 0.0000 & 0.0000 & 0.0000 & 0.0000 & 0.0000 \\
\hline
\end{tabular}




\begin{tabular}{|c|c|c|c|c|c|c|c|c|c|c|c|}
\hline \multicolumn{6}{|c|}{ Propiophenone + 1-butanol at $313.15 \mathrm{~K}$} & \multicolumn{6}{|c|}{ Propiophenone + 1-butanol at $318.15 \mathrm{~K}$} \\
\hline 0.0000 & 0.0000 & 0.0000 & 0.0000 & 0.0000 & 0.0000 & 0.0000 & 0.0000 & 0.0000 & 0.0000 & 0.0000 & 0.0000 \\
\hline 0.0710 & -0.2139 & -1.9638 & 1.4624 & 0.0077 & -0.6157 & 0.0710 & -0.2409 & -2.0534 & 1.7375 & 0.0082 & -0.6437 \\
\hline 0.1468 & -0.3943 & -3.4645 & 2.3982 & 0.0140 & -1.0861 & 0.1468 & -0.4399 & -3.5844 & 2.6733 & 0.0146 & -1.1237 \\
\hline 0.2278 & -0.5320 & -4.5035 & 2.7286 & 0.0186 & -1.4119 & 0.2278 & -0.5819 & -4.6572 & 3.1971 & 0.0195 & -1.4600 \\
\hline 0.3145 & -0.6200 & -5.1596 & 3.0688 & 0.0218 & -1.6175 & 0.3145 & -0.6705 & -5.3006 & 3.4169 & 0.0226 & -1.6617 \\
\hline 0.4077 & -0.6500 & -5.3936 & 3.1274 & 0.0233 & -1.6909 & 0.4077 & -0.6960 & -5.5233 & 3.4314 & 0.0240 & -1.7316 \\
\hline 0.5080 & -0.6085 & -5.2137 & 3.0866 & 0.0229 & -1.6345 & 0.5080 & -0.6545 & -5.3441 & 3.4722 & 0.0237 & -1.6754 \\
\hline 0.6163 & -0.4999 & -4.6159 & 2.9890 & 0.0205 & -1.4471 & 0.6163 & -0.5500 & -4.7478 & 3.4998 & 0.0215 & -1.4884 \\
\hline 0.7336 & -0.3395 & -3.5829 & 2.7694 & 0.0161 & -1.1232 & 0.7336 & -0.3900 & -3.7005 & 3.3209 & 0.0171 & -1.1601 \\
\hline 0.8610 & -0.1499 & -2.0669 & 2.0534 & 0.0094 & -0.6480 & 0.8610 & -0.1959 & -2.1555 & 2.5640 & 0.0104 & -0.6757 \\
\hline 1.0000 & 0.0000 & 0.0000 & 0.0000 & 0.0000 & 0.0000 & 1.0000 & 0.0000 & 0.0000 & 0.0000 & 0.0000 & 0.0000 \\
\hline \multicolumn{6}{|c|}{ Propiophenone +1 -pentanol at $313.15 \mathrm{~K}$} & \multicolumn{6}{|c|}{ Propiophenone +1-pentanol at $318.15 \mathrm{~K}$} \\
\hline 0.0000 & 0.0000 & 0.0000 & 0.0000 & 0.0000 & 0.0000 & 0.0000 & 0.0000 & 0.0000 & 0.0000 & 0.0000 & 0.0000 \\
\hline 0.0836 & -0.1570 & -1.6571 & 2.0082 & 0.0043 & -0.5195 & 0.0836 & -0.1970 & -1.8632 & 2.5082 & 0.0049 & -0.5841 \\
\hline 0.1703 & -0.2880 & -2.8007 & 2.7639 & 0.0073 & -0.8780 & 0.1703 & -0.3455 & -3.0864 & 3.2639 & 0.0079 & -0.9676 \\
\hline 0.2602 & -0.3819 & -3.5833 & 3.2905 & 0.0095 & -1.1234 & 0.2602 & -0.4449 & -3.9160 & 3.7905 & 0.0101 & -1.2277 \\
\hline 0.3537 & -0.4420 & -4.0272 & 3.6194 & 0.0110 & -1.2625 & 0.3537 & -0.4950 & -4.3755 & 4.1194 & 0.0114 & -1.3717 \\
\hline 0.4508 & -0.4520 & -4.1376 & 3.7605 & 0.0116 & -1.2971 & 0.4508 & -0.5010 & -4.4847 & 4.2605 & 0.0120 & -1.4060 \\
\hline 0.5518 & -0.4217 & -3.9349 & 3.7487 & 0.0113 & -1.2336 & 0.5518 & -0.4667 & -4.2612 & 4.2487 & 0.0117 & -1.3359 \\
\hline 0.6570 & -0.3450 & -3.4142 & 3.4702 & 0.0100 & -1.0704 & 0.6570 & -0.3960 & -3.7049 & 3.9702 & 0.0106 & -1.1615 \\
\hline 0.7665 & -0.2350 & -2.5884 & 2.9131 & 0.0078 & -0.8115 & 0.7665 & -0.2875 & -2.8218 & 3.4131 & 0.0084 & -0.8846 \\
\hline 0.8808 & -0.1099 & -1.4655 & 2.0264 & 0.0046 & -0.4594 & 0.8808 & -0.1569 & -1.6199 & 2.5264 & 0.0054 & -0.5078 \\
\hline 1.0000 & 0.0000 & 0.0000 & 0.0000 & 0.0000 & 0.0000 & 1.0000 & 0.0000 & 0.0000 & 0.0000 & 0.0000 & 0.0000 \\
\hline
\end{tabular}

1-propanol, 1-butanol and 1-pentanol at 303.15, 308.15, 313.15 and $318.15 \mathrm{~K}$. In present study, $\mathrm{V}^{\mathrm{E}}$ is negative for the binary mixtures over the entire composition range for all four temperatures. It shows the predominance of specific interactions and it results in decrease in volume which includes depolymerization of self-associated 1-alcohols by the addition of propiophenone or formation of new bonds (hydrogen bond) between propiophenone and alcohols and other complex forming interactions [51].

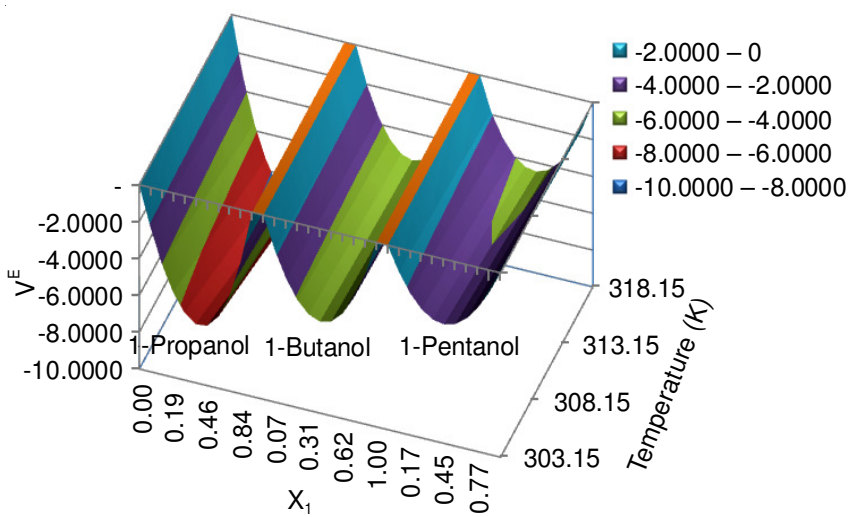

Fig. 1. Combined 3D details of $\mathrm{V}^{\mathrm{E}}$ with mole fraction at temperatures 303.15-318.15 K for propiophenone + (1-propanol, 1-butanol and 1-pentanol)

As suggested by Sah et al. [52] excess molar volume is the resultant effect of physical contribution which is nonspecific interaction (dispersion type) between the real species causing positive $\mathrm{V}^{\mathrm{E}}$, chemical which is specific interaction may due to charge transfer type forces and other complex forming interaction resulting negative $\mathrm{V}^{\mathrm{E}}$ and structural contribution arising from interstitial accommodation and changes in free volume also causes negative $\mathrm{V}^{\mathrm{E}}$. However, the positive values of $\mathrm{V}^{\mathrm{E}}$ are due to physical interaction mainly consisting of dispersion force or weak dipolar-dipolar interactions.
Figs. $1 \& 2$ and Table- 3 illustrates that the excess molar volumes for all the three binary systems over the whole composition range are negative and the value decreases with increase in temperatures at $303.15,308.15,313.15$ and $318.15 \mathrm{~K}$. The maximum deviation in excess molar volume is obtained at 0.3601, 0.4077 and 0.4508 mole fractions of propiophenone for (propiophenone + 1-propanol), propiophenone + 1-butanol) and (propiophenone +1 -pentanol) respectively at $303.15 \mathrm{~K}$.

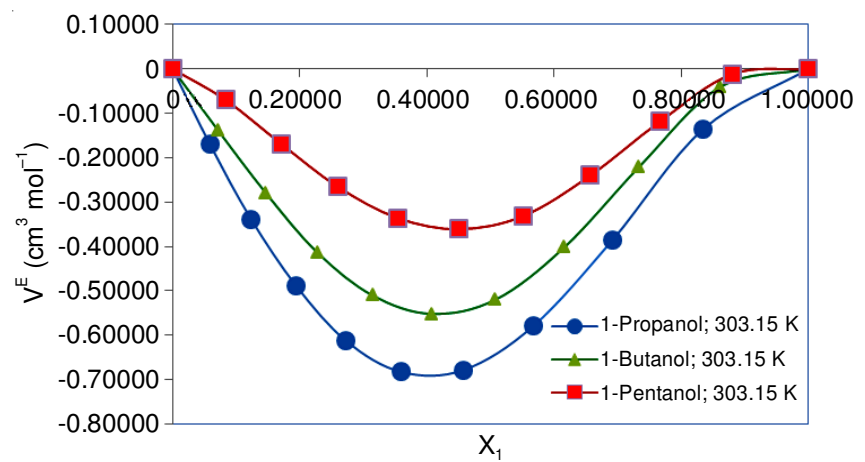

Fig. 2. $\quad \mathrm{V}^{\mathrm{E}}$ with mole fraction for propiophenone + (1-propanol, 1-butanol and 1-pentanol) at $303.15 \mathrm{~K}$

The order of $\mathrm{V}^{\mathrm{E}}$ values under the current study is 1-propanol $<1$-butanol $<1$-pentanol. $\mathrm{V}^{\mathrm{E}}$ negative values are increasing with increase in temperatures. It shows that the extent of hydrogen bond and self-association decreases with increasing chain length of the alkanols [53].

Deviations in isentropic compressibility $\left(\Delta \mathbf{K}_{\mathrm{s}}\right)$ : Figs. 3 and 4 shows that $\Delta K s$ values are negative over the whole composition range at the four temperatures. In the current study, the $\Delta \mathrm{Ks}$ values are negative because of strong molecular interactions between priopiophenone and 1-alkanols. Kiyohara and Benson [54] suggested that $\Delta \mathrm{Ks}$ is the result of several opposing effects. Strong molecular interactions occur through charge transfer, dipole induced-dipole and dipole-dipole interactions 


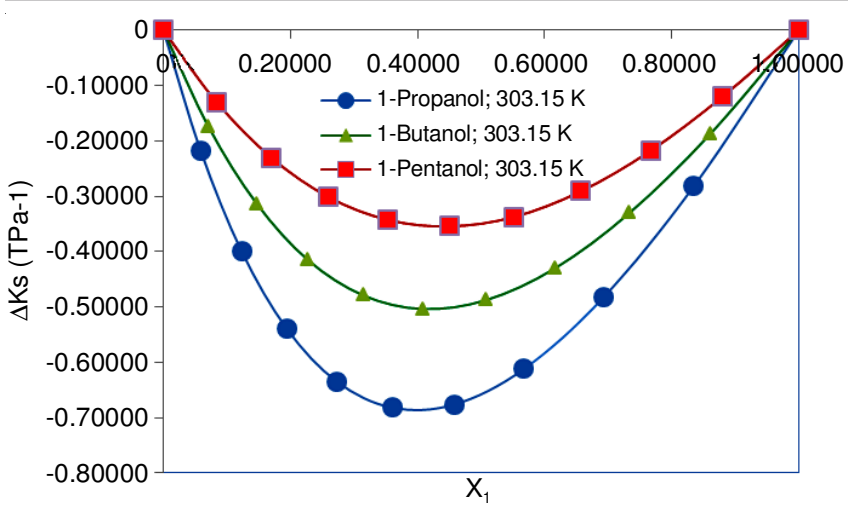

Fig. 3. Deviation in isentropic compressibility for propiophenone $+(1-$ propanol, 1-butanol and 1-pentanol) at $303.15 \mathrm{~K}$

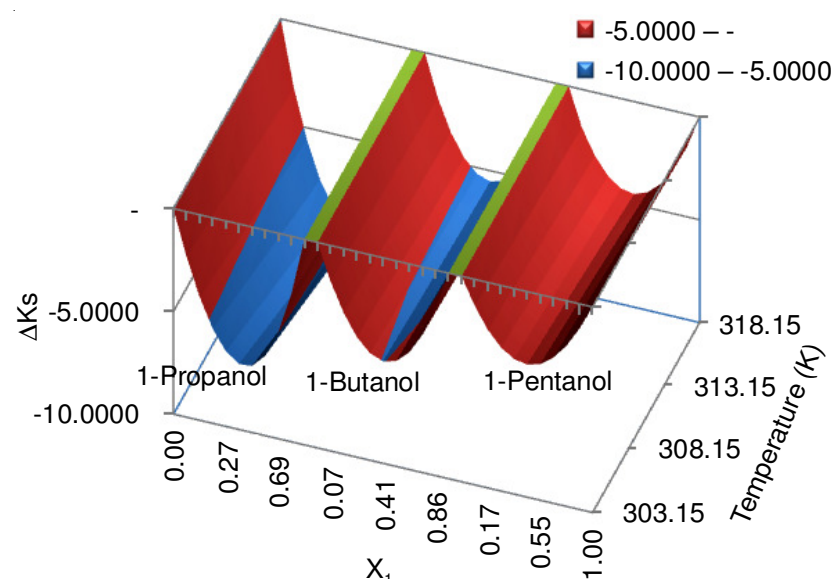

Fig. 4. Combined 3D details of deviation in isentropic compressibility for propiophenone + (1-propanol, 1-butanol and 1-pentanol) at 303.15$318.15 \mathrm{~K}$

[55], closer approach of unlike molecules tends to contraction in the volume and reduction in the size leads to a more compact structure making $\Delta \mathrm{Ks}$ negative, whereas de-clustering of the 1 -alkanol structures tends to make $\Delta \mathrm{Ks}$ positive. Fort and Moore [56] notice that the negative excess free volume tends to decrease as the strength of the interaction between the unlike molecules increases although they do not parallel with the excess compressibility. The trend is negative, order of $\Delta \mathrm{Ks}$ values is propanol $<$ butanol $<$ pentanol.

Excess intermolecular free length $\left(\mathbf{L}_{f}{ }^{\mathbf{E}}\right)$ : In Figs. 5 and $6, \mathrm{~L}_{\mathrm{f}}^{\mathrm{E}}$ values are negative for the whole composition range at all four temperatures. According to Ramamoorthy and Alwan [57]

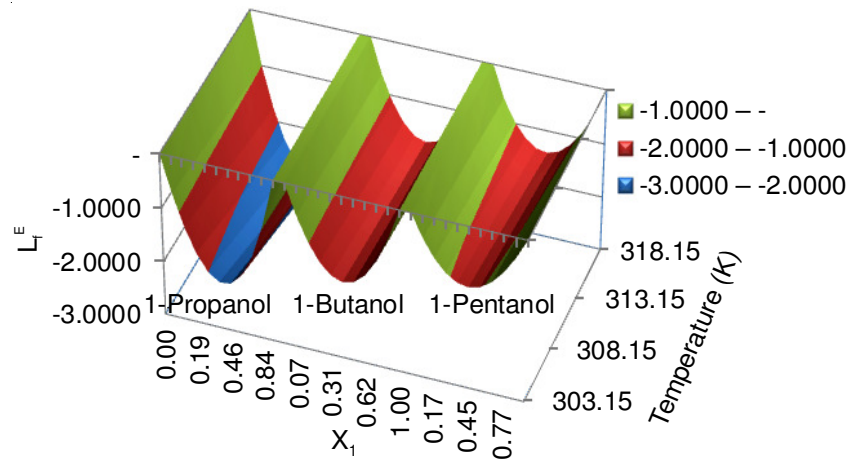

Fig. 5. Combined 3D details for variation of excess intermolecular free length with mole fraction of propiophenone + (1-propanol, 1-butanol and 1-pentanol) at 303.15-318.15 K

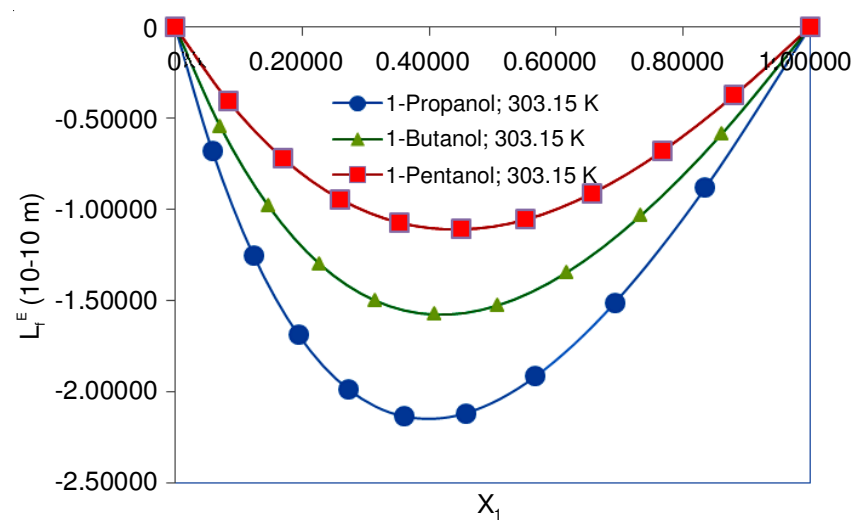

Fig. 6. Variation of excess intermolecular free length with mole fraction of propiophenone with 1-propanol, 1-butanol and 1-pentanol at $303.15 \mathrm{~K}$

negative values of excess intermolecular free length $\mathrm{L}_{\mathrm{f}}^{\mathrm{E}}$ indicate that sound waves cover longer distances due to decrease in intermolecular free length ascribing the dominant nature of hydrogen bond interaction between unlike molecules.

In this study, it is observed that the values of excess intermolecular free length and $\Delta \mathrm{Ks}$ are negative. It shows strong intermolecular interactions between the unlike molecules in the binary system. The trend of $\left(\mathrm{L}_{\mathrm{f}}^{\mathrm{E}}\right)$ is negative and the order of values are propanol $<$ butanol $<$ pentanol.

Deviation in ultrasonic speed $(\Delta \mathrm{U})$ and deviation in acoustic impedance $(\Delta \mathbf{Z})$ : Table-3 shows that the values of $\Delta \mathrm{U}$ are positive for all the binary mixtures of propiophenone with 1-propanol, 1-butanol and 1-pentanol. Generally, negative values of indicate dispersion forces due to weak interactions whereas positive values of $\Delta \mathrm{U}$ indicate strong interactions [58]. The sign and magnitude of $\Delta U$ play important roles in describing molecular rearrangements among the component molecules in the mixtures which reflect intermolecular interactions between the molecules.

Figs. 7 and 8 show that the $\Delta \mathrm{U}$ values are positive for the whole composition range at four temperatures for the current binary mixtures. The trend is positive in $\Delta \mathrm{U}$ and order of values is 1-propanol < 1-butanol < 1-pentanol. In the current study, $\Delta \mathrm{Z}$ values are also positive for the whole composition range at all four temperatures (Fig. 9). The trend is positive in $\Delta \mathrm{Z}$ and the order of values is 1 -propanol $<1$-butanol $<1$-pentanol.

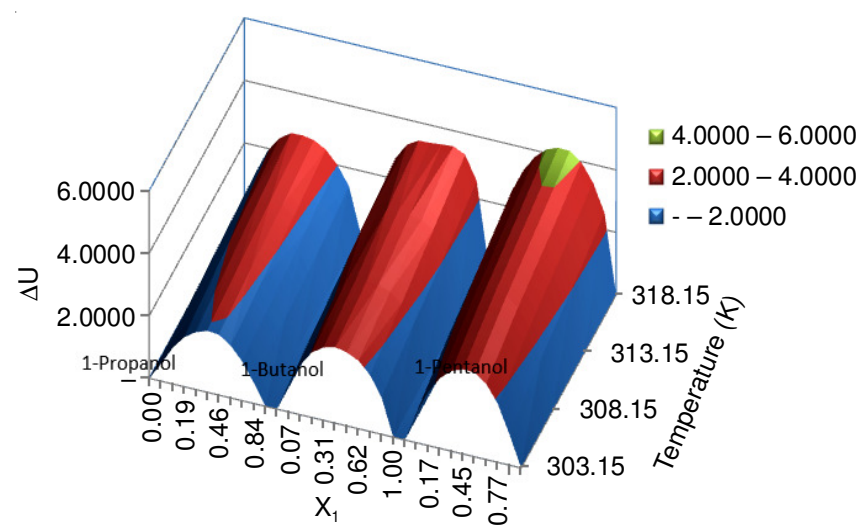

Fig. 7. Deviation in ultrasonic speed velocity with mole fraction of propiophenone with 1-propanol, 1-butanol and 1-pentanol at 303.15-318.15 K 


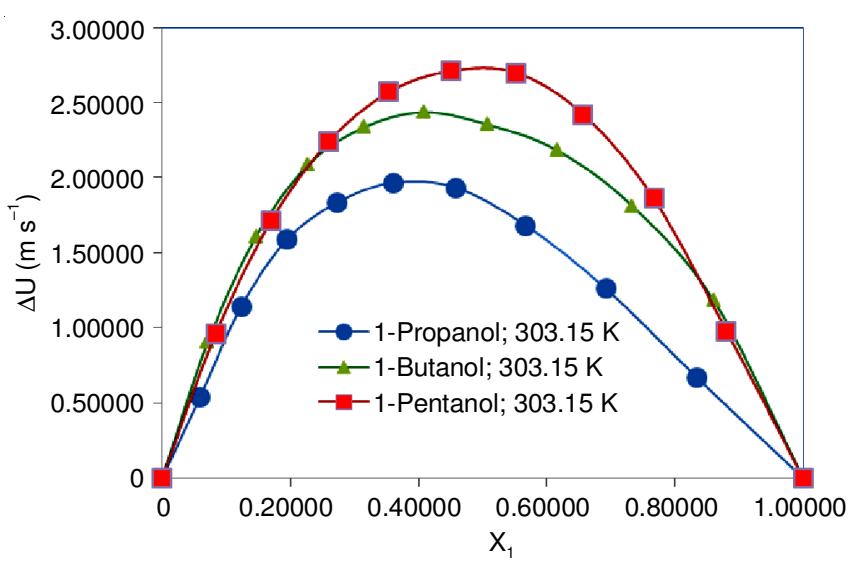

Fig. 8. Deviation in ultrasonic speed velocity with mole fraction of propiophenone with 1-propanol, 1-butanol and 1-pentanol at 303.15 K

Partial molar volume (PMV): Behaviour of the mixtures is further analyzed by calculating the partial excess molar volumes of the components. $\mathrm{V}_{\mathrm{m} 1}^{\mathrm{E}}$ and $\mathrm{V}_{\mathrm{m} 2}^{\mathrm{E}}$ for each 1-alkanols are calculated with respect to their mole fractions at all four temperatures $303.15,308.15,313.15$ and $318.15 \mathrm{~K}$.

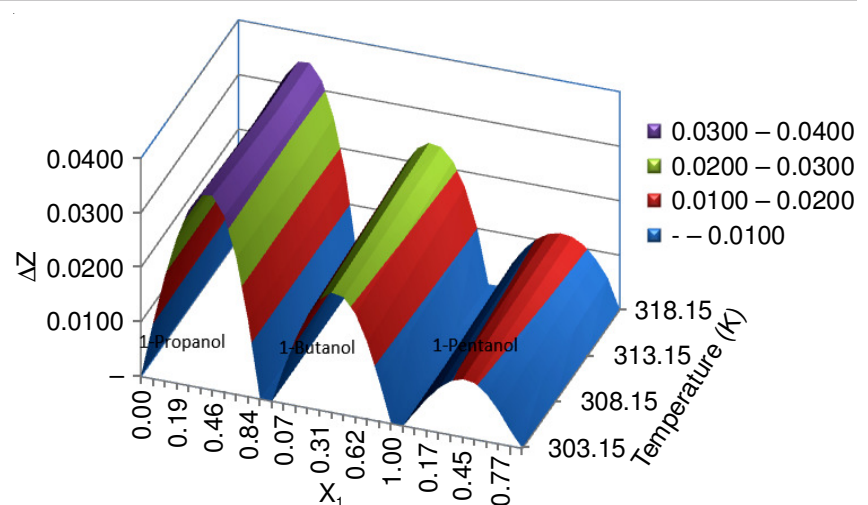

Fig. 9. Combined 3D details for deviation in acoustic impedance with mole fraction of propiophenone + (1-propanol, 1-butanol and 1-pentanol) at $303.15-318.15 \mathrm{~K}$

The partial molar volumes, $\overline{\mathrm{V}}_{\mathrm{m}, 1}^{\circ}$ of component 1 (propiophenone) and $\overline{\mathrm{V}}_{\mathrm{m}, 2}^{\circ}$ of component 2 (1-propanol, 1-butanol, 1-pentanol) in the mixture over entire composition range are calculated using the following relations:

$$
\overline{\mathrm{V}}_{\mathrm{m}, 1}^{\mathrm{o}}=\mathrm{V}_{\mathrm{m}}^{\mathrm{E}}+\mathrm{V}_{\mathrm{m}, 1}^{*}+\mathrm{x}_{2}\left(\frac{\partial \mathrm{V}_{\mathrm{m}}^{\mathrm{E}}}{\partial \mathrm{x}_{1}}\right) \mathrm{T}, \mathrm{P}
$$

TABLE-4

EXCESS PARTIAL MOLAR VOLUME AT 303.15, 308.15, 313.15 AND 318.15 K

\begin{tabular}{|c|c|c|c|c|c|c|c|c|}
\hline \multirow[b]{2}{*}{$\mathrm{x}_{1}$} & \multicolumn{2}{|c|}{$303.15 \mathrm{~K}$} & \multicolumn{2}{|c|}{$308.15 \mathrm{~K}$} & \multicolumn{2}{|c|}{$313.15 \mathrm{~K}$} & \multicolumn{2}{|c|}{$318.15 \mathrm{~K}$} \\
\hline & $\overline{\mathrm{V}}_{\mathrm{m}, 1}^{\mathrm{E}}$ & $\overline{\mathrm{V}}_{\mathrm{m}, 2}^{\mathrm{E}}$ & $\overline{\mathrm{V}}_{\mathrm{m}, \mathrm{l}}^{\mathrm{E}}$ & $\overline{\mathrm{V}}_{\mathrm{m}, 2}^{\mathrm{E}}$ & $\overline{\mathrm{V}}_{\mathrm{m}, 1}^{\mathrm{E}}$ & $\overline{\mathrm{V}}_{\mathrm{m}, 2}^{\mathrm{E}}$ & $\overline{\mathrm{V}}_{\mathrm{m}, 1}^{\mathrm{E}}$ & $\overline{\mathrm{V}}_{\mathrm{m}, 2}^{\mathrm{E}}$ \\
\hline \multicolumn{9}{|c|}{ Propiophenone + 1-propanol } \\
\hline 0.0000 & 0.2232 & 0.0000 & 0.0853 & 0.0000 & -0.0439 & 0.0000 & -0.1660 & 0.0000 \\
\hline 0.0588 & -0.4890 & 0.0167 & -0.5796 & 0.0157 & -0.6675 & 0.0148 & -0.7517 & 0.0140 \\
\hline 0.1233 & -1.0177 & 0.0567 & -1.0722 & 0.0533 & -1.1277 & 0.0501 & -1.1821 & 0.0472 \\
\hline 0.1943 & -1.3504 & 0.0992 & -1.3800 & 0.0930 & -1.4122 & 0.0870 & -1.4450 & 0.0813 \\
\hline 0.2728 & -1.4818 & 0.1134 & -1.4970 & 0.1053 & -1.5147 & 0.0967 & -1.5337 & 0.0885 \\
\hline 0.3601 & -1.4184 & 0.0567 & -1.4281 & 0.0485 & -1.4389 & 0.0387 & -1.4509 & 0.0290 \\
\hline 0.4577 & -1.1844 & -0.1262 & -1.1949 & -0.1322 & -1.2042 & -0.1416 & -1.2143 & -0.1513 \\
\hline 0.5676 & -0.8300 & -0.4998 & -0.8432 & -0.5033 & -0.8534 & -0.5120 & -0.8637 & -0.5217 \\
\hline 0.6924 & -0.4375 & -1.1226 & -0.4505 & -1.1316 & -0.4603 & -1.1454 & -0.4696 & -1.1605 \\
\hline 0.8351 & -0.1213 & -2.0047 & -0.1281 & -2.0495 & -0.1332 & -2.0906 & -0.1379 & -2.1316 \\
\hline 1.0000 & 0.0000 & -2.9957 & 0.0000 & -3.1608 & 0.0000 & -3.2926 & 0.0000 & -3.4167 \\
\hline \multicolumn{9}{|c|}{ Propiophenone + 1-butanol } \\
\hline 0.0000 & 0.5768 & 0.0000 & 0.1054 & 0.0000 & -0.6599 & 0.0000 & -1.2043 & 0.0000 \\
\hline 0.0710 & -0.3411 & 0.0247 & -0.5877 & 0.0192 & -1.0509 & 0.0113 & -1.4032 & 0.0061 \\
\hline 0.1468 & -0.9419 & 0.0760 & -1.0387 & 0.0592 & -1.2890 & 0.0332 & -1.5025 & 0.0158 \\
\hline 0.2278 & -1.2504 & 0.1152 & -1.2631 & 0.0892 & -1.3796 & 0.0437 & -1.5020 & 0.0122 \\
\hline 0.3145 & -1.3046 & 0.0992 & -1.2862 & 0.0731 & -1.3344 & 0.0151 & -1.4052 & -0.0280 \\
\hline 0.4077 & -1.1572 & -0.0161 & -1.1446 & -0.0291 & -1.1724 & -0.0874 & -1.2208 & -0.1364 \\
\hline 0.5080 & -0.8762 & -0.2684 & -0.8874 & -0.2572 & -0.9220 & -0.3052 & -0.9649 & -0.3561 \\
\hline 0.6163 & -0.5427 & -0.6755 & -0.5762 & -0.6440 & -0.6224 & -0.6860 & -0.6638 & -0.7442 \\
\hline 0.7336 & -0.2435 & -1.2107 & -0.2811 & -1.2010 & -0.3251 & -1.2815 & -0.3582 & -1.3772 \\
\hline 0.8610 & -0.0534 & -1.7607 & -0.0725 & -1.8936 & -0.0936 & -2.1412 & -0.1081 & -2.3562 \\
\hline 1.0000 & 0.0000 & -2.0520 & 0.0000 & -2.5970 & 0.0000 & -3.3008 & 0.0000 & -3.8144 \\
\hline \multicolumn{9}{|c|}{ Propiophenone + 1-pentanol } \\
\hline 0.0000 & 0.6595 & 0.0000 & -0.0365 & 0.0000 & -0.7312 & 0.0000 & -1.3571 & 0.0000 \\
\hline 0.0836 & -0.1635 & 0.0242 & -0.5540 & 0.0150 & -0.9421 & 0.0058 & -1.3014 & -0.0022 \\
\hline 0.1703 & -0.6259 & 0.0651 & -0.8246 & 0.0376 & -1.0198 & 0.0097 & -1.2107 & -0.0145 \\
\hline 0.2602 & -0.8023 & 0.0789 & -0.8973 & 0.0355 & -0.9880 & -0.0087 & -1.0865 & -0.0474 \\
\hline 0.3537 & -0.7708 & 0.0304 & -0.8242 & -0.0190 & -0.8726 & -0.0695 & -0.9322 & -0.1148 \\
\hline 0.4508 & -0.6106 & -0.1016 & -0.6587 & -0.1460 & -0.7017 & -0.1917 & -0.7537 & -0.2346 \\
\hline 0.5518 & -0.3973 & -0.3169 & -0.4532 & -0.3536 & -0.5045 & -0.3912 & -0.5603 & -0.4305 \\
\hline 0.6570 & -0.1974 & -0.5833 & -0.2557 & -0.6316 & -0.3103 & -0.6789 & -0.3654 & -0.7324 \\
\hline 0.7665 & -0.0595 & -0.8237 & -0.1043 & -0.9433 & -0.1469 & -1.0579 & -0.1880 & -1.1790 \\
\hline 0.8808 & -0.0026 & -0.8978 & -0.0207 & -1.2150 & -0.0381 & -1.5196 & -0.0544 & -1.8195 \\
\hline 1.0000 & 0.0000 & -0.5786 & 0.0000 & -1.3212 & 0.0000 & -2.0381 & 0.0000 & -2.7165 \\
\hline
\end{tabular}




$$
\overline{\mathrm{V}}_{\mathrm{m}, 2}^{\mathrm{o}}=\mathrm{V}_{\mathrm{m}}^{\mathrm{E}}+\mathrm{V}_{\mathrm{m}, 2}^{*}-\mathrm{x}_{1}\left(\frac{\partial \mathrm{V}_{\mathrm{m}}^{\mathrm{E}}}{\partial \mathrm{x}_{1}}\right) \mathrm{T}, \mathrm{P}
$$

where, $\mathrm{V}_{\mathrm{m}, 1}^{*}, \mathrm{~V}_{\mathrm{m}, 2}^{*}$ are molar volumes of pure components propiophenone with 1-propanol, 1-butanol and 1-pentanol. The derivative of $\left(\frac{\partial \mathrm{V}_{\mathrm{m}}^{\mathrm{E}}}{\partial \mathrm{x}_{1}}\right)$ obtained by using below equations.

$$
\begin{aligned}
& \overline{\mathrm{V}}_{\mathrm{m}, 2}^{\mathrm{o}}=\mathrm{V}_{\mathrm{m}, 2}^{*}+\mathrm{x}_{1}^{2} \sum_{\mathrm{i}=0}^{\mathrm{n}} \mathrm{A}_{\mathrm{i}}\left(1-2 \mathrm{x}_{1}\right)^{\mathrm{i}}+2 \mathrm{x}_{1} \mathrm{x}_{2}^{2} \sum_{\mathrm{i}=1}^{\mathrm{n}} \mathrm{A}_{\mathrm{i}}\left(1-2 \mathrm{x}_{1}\right)^{\mathrm{i}-1} \\
& \overline{\mathrm{V}}_{\mathrm{m}, 1}^{\mathrm{o}}=\mathrm{V}_{\mathrm{m}, 1}^{*}+\mathrm{x}_{2}^{2} \sum_{\mathrm{i}=0}^{\mathrm{n}} \mathrm{A}_{\mathrm{i}}\left(1-2 \mathrm{x}_{1}\right)^{\mathrm{i}}+2 \mathrm{x}_{1} \mathrm{x}_{2}^{2} \sum_{\mathrm{i}=1}^{\mathrm{n}} \mathrm{A}_{\mathrm{i}}\left(1-2 \mathrm{x}_{1}\right)^{\mathrm{i}-1}
\end{aligned}
$$

The excess partial molar volumes $\overline{\mathrm{V}}_{\mathrm{m}, 1}^{\mathrm{oE}}, \overline{\mathrm{V}}_{\mathrm{m}, 2}^{\mathrm{o}, \mathrm{E}}$ over the whole composition range are calculated by using the below relation [59]:

$$
\begin{aligned}
& \overline{\mathrm{V}}_{\mathrm{m}, 1}^{\mathrm{o}, \mathrm{E}}=\overline{\mathrm{V}}_{\mathrm{m}, 1}^{\mathrm{o}}-\mathrm{V}_{\mathrm{m}, 1}^{\mathrm{*}} \\
& \overline{\mathrm{V}}_{\mathrm{m}, 2}^{\mathrm{o}, \mathrm{E}}=\overline{\mathrm{V}}_{\mathrm{m}, 2}^{\mathrm{o}}-\mathrm{V}_{\mathrm{m}, 2}^{*}
\end{aligned}
$$

The values of excess partial molar volumes are given in Table-4. The negative excess partial molar volumes may be indicative of solute-solvent $[60,61]$ interactions between unlike molecules, whereas positive values indicate the presence of strong self-association between like molecules. The excess partial molar volume of propiophenone with alkanols at infinite dilution are calculated by using the relation:

$$
\begin{aligned}
& \overline{\mathrm{V}}_{\mathrm{m}, 2}^{\mathrm{o}, \mathrm{E}, \infty}=\overline{\mathrm{V}}_{\mathrm{m}, 2}^{\mathrm{o}, \infty}-\mathrm{V}_{\mathrm{m}, 2}^{*} \\
& \overline{\mathrm{V}}_{\mathrm{m}, 1}^{\mathrm{o}, \mathrm{E}, \infty}=\overline{\mathrm{V}}_{\mathrm{m}, 1}^{\mathrm{o}, \infty}-\mathrm{V}_{\mathrm{m}, 1}^{*}
\end{aligned}
$$

The values of excess partial molar volume of at infinite dilution $\overline{\mathrm{V}}_{\mathrm{m}, 1}^{\mathrm{o}, \mathrm{E}, \infty}, \overline{\mathrm{V}}_{\mathrm{m}, 2}^{\mathrm{o}, \mathrm{E}, \infty}$ for the selected binary systems at different temperatures are presented in Table-5. Negative values of $\overline{\mathrm{V}}_{\mathrm{m}, 1}^{\mathrm{o}, \mathrm{E}, \infty}, \overline{\mathrm{V}}_{\mathrm{m}, 2}^{\mathrm{o}, \mathrm{E}, \infty}$ of propiophenone with 1-alkanols shows stronger solute-solvent interactions at infinite dilution. Fig. 10 shows the behaviour of excess partial molar volume at $303.15 \mathrm{~K}$.

Redlich-Kister equation: The variation of $\mathrm{V}^{\mathrm{E}}, \mathrm{K}_{\mathrm{s}}^{\mathrm{E}}, \Delta \mathrm{Z}$, $\Delta \mathrm{U}$ and $\mathrm{L}_{\mathrm{f}}^{\mathrm{E}}$ with mole fraction were fitted to the Redlich-Kister equation of the type:

$$
\mathrm{Y}^{\mathrm{E}}=\mathrm{X}_{\mathrm{i}} \mathrm{X}_{2}\left\{\mathrm{a} 0+\mathrm{a} 1\left(\mathrm{x}_{1}-\mathrm{X}_{2}\right)+\mathrm{a} 2\left(\mathrm{x}_{1}-\mathrm{X}_{2}\right)^{2}\right\}
$$

\begin{tabular}{|c|c|c|c|c|c|c|}
\hline \multicolumn{7}{|c|}{$\begin{array}{c}\text { TABLE-5 } \\
\text { EXCESS PARTIAL MOLAR VOLUME AT INFINITE DILUTION }\end{array}$} \\
\hline Temp. (K) & $\overline{\mathrm{V}}_{\mathrm{m}, 1}^{\mathrm{o}}\left(\mathrm{cm}^{3} \mathrm{~mol}^{-1}\right)$ & $\mathrm{V}_{\mathrm{m}, \mathrm{1}}^{*}\left(\mathrm{~cm}^{3} \mathrm{~mol}^{-1}\right)$ & $\overline{\mathrm{V}}_{\mathrm{m}, 1}^{\mathrm{o}, \mathrm{E}}\left(\mathrm{cm}^{3} \mathrm{~mol}^{-1}\right)$ & $\overline{\mathrm{V}}_{\mathrm{m}, 2}^{\mathrm{o}}\left(\mathrm{cm}^{3} \mathrm{~mol}^{-1}\right)$ & $\mathrm{V}_{\mathrm{m}, 2}^{*}\left(\mathrm{~cm}^{3} \mathrm{~mol}^{-1}\right)$ & $\overline{\mathrm{V}}_{\mathrm{m}, 2}^{\mathrm{o}, \mathrm{E}}\left(\mathrm{cm}^{3} \mathrm{~mol}^{-1}\right)$ \\
\hline \multicolumn{7}{|c|}{ Propiophenone + 1-propanol } \\
\hline 303.15 & 133.8021 & 133.5789 & 0.2232 & 72.5733 & 75.5690 & -2.9957 \\
\hline 308.15 & 134.0644 & 133.9790 & 0.0853 & 72.7806 & 75.9414 & -3.1608 \\
\hline 313.15 & 134.3376 & 134.3816 & -0.0439 & 73.0443 & 76.3368 & -3.2926 \\
\hline 318.15 & 134.6206 & 134.7865 & -0.1660 & 73.3001 & 76.7169 & -3.4167 \\
\hline \multicolumn{7}{|c|}{ Propiophenone + 1-butanol } \\
\hline 303.15 & 134.1557 & 133.5789 & 0.5768 & 90.3418 & 92.3938 & -2.0520 \\
\hline 308.15 & 134.0844 & 133.9790 & 0.1054 & 90.2633 & 92.8603 & -2.5970 \\
\hline 313.15 & 133.7217 & 134.3816 & -0.6599 & 90.0166 & 93.3174 & -3.3008 \\
\hline 318.15 & 133.5822 & 134.7865 & -1.2043 & 89.9611 & 93.7755 & -3.8144 \\
\hline \multicolumn{7}{|c|}{ Propiophenone + 1-pentanol } \\
\hline 303.15 & 134.2384 & 133.5789 & 0.6595 & 108.5720 & 109.1506 & -0.5786 \\
\hline 308.15 & 133.9425 & 133.9790 & -0.0365 & 108.3181 & 109.6393 & -1.3212 \\
\hline 313.15 & 133.6504 & 134.3816 & -0.7312 & 108.1219 & 110.1600 & -2.0381 \\
\hline 318.15 & 133.4295 & 134.7865 & -1.3571 & 108.0247 & 110.7412 & -2.7165 \\
\hline
\end{tabular}

where $\mathrm{Y}^{\mathrm{E}}$ is for $\mathrm{V}^{\mathrm{E}}, \Delta \mathrm{U}, \Delta \mathrm{Ks}, \Delta \mathrm{Z}$ and $\mathrm{L}_{\mathrm{f}}^{\mathrm{E}}$ in the polynomial degree. The values of a0, a1 and a2 are the coefficients of the polynomial equation and were obtained by the method of leastsquares and are given in Table- 6 along with standard deviation values. The standard deviations are calculated by using the equation:
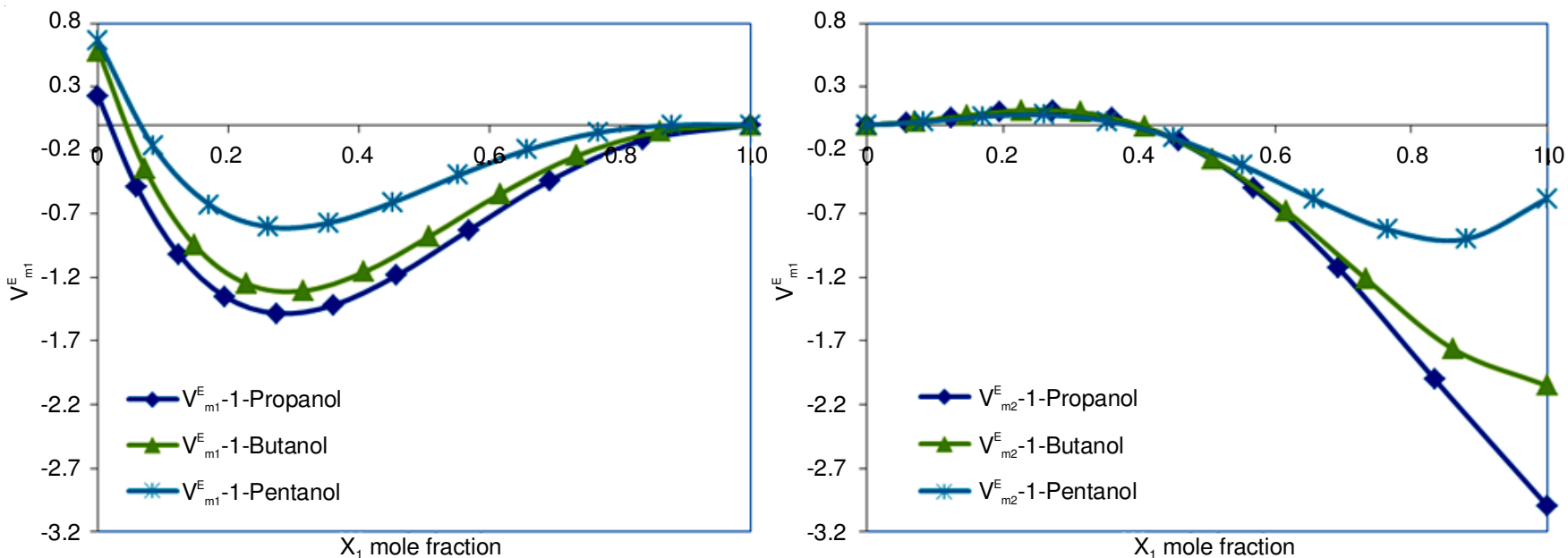

Fig. 10. Excess partial molar volume $\mathrm{V}_{\mathrm{m}, 1}^{\mathrm{E}}$ and $\mathrm{V}_{\mathrm{m}, 2}^{\mathrm{E}}$ for the components 1-propanol, 1-butanol and 1-pentanol at $303.15 \mathrm{~K}$ 


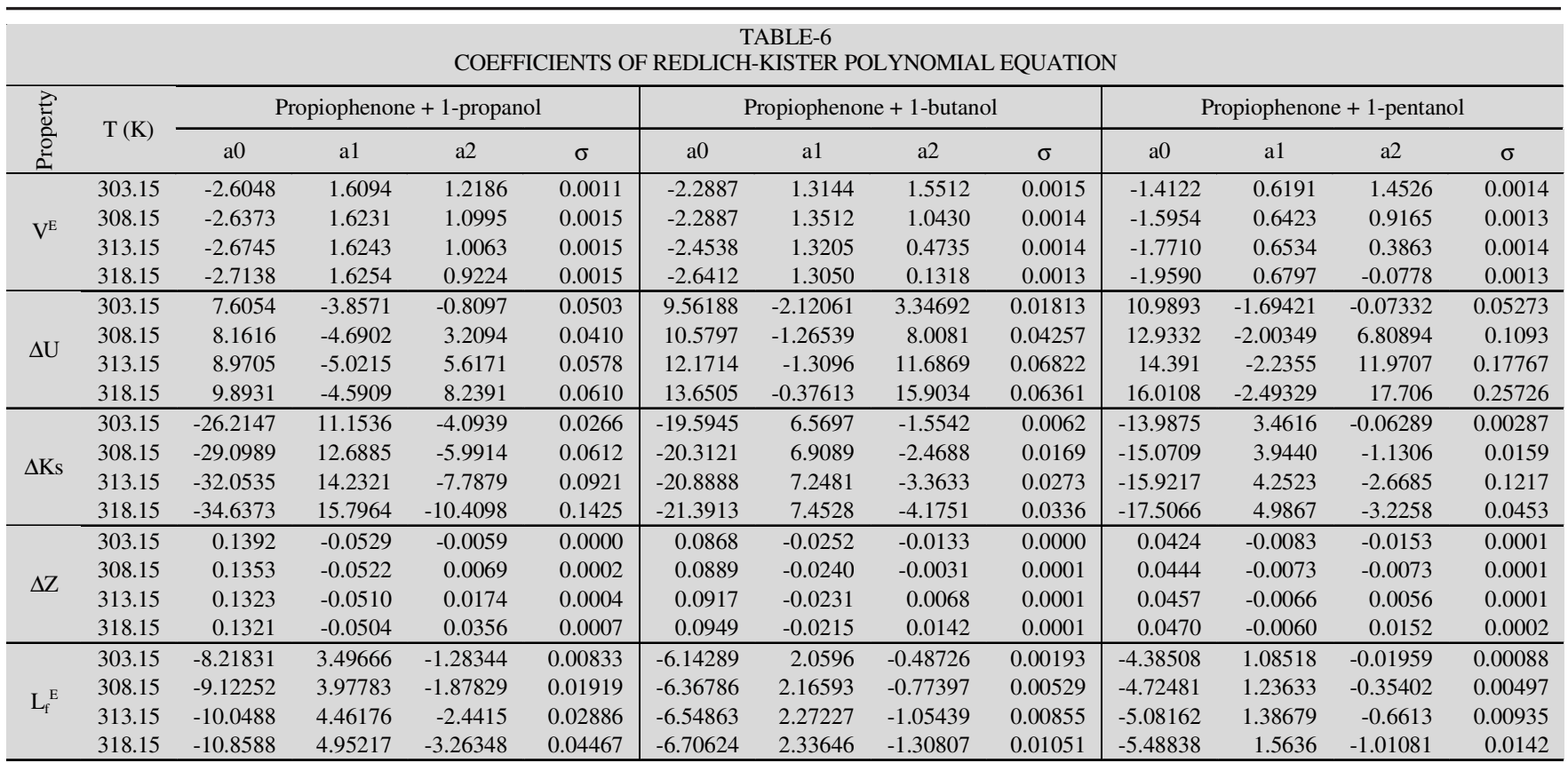

$$
\sigma\left(\mathrm{Y}^{\mathrm{E}}\right)=\frac{\left\{\Sigma_{\mathrm{i}=1}^{\mathrm{n}}\left(\mathrm{Y}_{\mathrm{obs}}^{\mathrm{E}}-\mathrm{Y}_{\text {cal }}^{\mathrm{E}}\right)^{2}\right\}^{1 / 2}}{\mathrm{n}-\mathrm{m}}
$$

where $\mathrm{n}$ is the total number of experimental points and $\mathrm{m}$ is the number of coefficients.

\section{Conclusion}

In this paper, the excess thermodynamic properties show that molecular interactions are predominant in the binary mixtures. The negative values of $\mathrm{V}^{\mathrm{E}}$ are due to the strong intermolecular attractions between unlike molecules. The current study shows that the strong dipole-dipole interactions are observed in 1-propanol as compared to that of 1-butanol and 1-pentanol. From the measured thermodynamic properties data, the values of excess molar volumes, deviation in acoustic impedance, excess free length, deviation in speed of sound and excess isentropic compressibility have been correlated by Redlich-Kister type polynomial equation to derive the coefficients and standard deviation. Excess partial molar volume values at infinite dilution indicate stronger solute-solvent interactions. Finally, the strength of interactions is more in 1-propanol than that of 1-butanol and 1-pentanol.

\section{ACKNOWLEDGEMENTS}

One of the authors, Mrs. Nanduri Gayatri Devi is highly thankful to University Grants Commission (UGC) New Delhi, India for providing a teacher fellowship and expresses her gratitude to the Management of Ch.S.D. St. Theresa's Autonomous College for Women, Eluru, India.

\section{REFERENCES}

1. T.S. Jyostna and N. Satyanarayana, Indian J. Chem., 44A, 1365 (2005).

2. H. Kumar and S. Chahal, J. Solution Chem., 3, 165 (2011); https://doi.org/10.1007/s10953-010-9645-3.

3. T.S. Rao, N. Veeraiah and C. Rambabu, Indian J. Pure Appl. Phys., 40, 850 (2002)

4. A.A. Mohammad, K.H.A.E. Alkhaldi, M.S. AlTuwaim and A.S. Al-Jimaz, J. Chem. Thermodyn., 56, 106 (2013); https://doi.org/10.1016/j.jct.2012.06.023
5. M. Almasi and H. Iloukhani, J. Chem. Eng. Data, 55, 3918 (2010); https://doi.org/10.1021/je901067c.

6. H. Kumar and S. Chahal, J. Solution Chem., 40, 165 (2011); https://doi.org/10.1007/s10953-010-9645-3.

7. M.G. Sankar, P. Venkateswarlu, K.S. Kumar and S. Sivarambabu, J. Mol. Liq., 173, 172 (2012);

https://doi.org/10.1016/j.molliq.2012.06.010.

8. V. Syamala, P. Venkateswarlu and K.S. Kumar, J. Chem. Eng. Data, 51, 928 (2006); https://doi.org/10.1021/je0504131.

9. A.B. Sawant, M. Hasan and V.J. Naukudkar, Chem. Sci. Trans., 2, 263 (2012);

https://doi.org/10.7598/cst2013.329.

10. A.C.H. Chandrasekhar, S.K. Ramanjaneyulu and A. Krishnaiah, Phys. Chem. Liq., 19, 171 (1989); https://doi.org/10.1080/00319108908030616.

11. S.J. Tangeda and S. Nallani, J. Chem. Eng. Data, 50, 89 (2005); https://doi.org/10.1021/je040008e.

12. K. Saravanakumar, R. Baskaran and T.R. Kubendran, J. Korean Chem. Soc., 56, 424 (2012); https://doi.org/10.5012/ikcs.2012.56.4.424.

13. S.K. Bindhani, G.K. Roy, Y.K. Mohanty and T.R. Kubendran, Russian J. Phys. Chem. A, 89, 1828 (2015); https://doi.org/10.1134/S0036024415100040.

14. T. Savithajyostna, G. Sowjanya, E. Jayanthi Rani, N. Raghuram, G. Ramesh and R. Suresh, Mater. Today: Proceed., 3, 4070 (2016); https://doi.org/10.1016/j.matpr.2016.11.075.

15. A. Ali, A.K. Nain, V.K. Sharma and S. Ahmad, Indian J. Pure Appl. Phys., 42, 666 (2004).

16. P.S. Nikam, L.N. Shirsat and M. Hasan, J. Chem. Eng. Data, 43, 732 (1998); https://doi.org/10.1021/je980028e.

17. P.S. Nikam, M.C. Jadhav and M. Hasan, J. Mol. Liq., 76, 1 (1998); https://doi.org/10.1016/S0167-7322(97)00051-2.

18. P.S. Nikam, M.C. Jadhav and M. Hasan, Acustica Acta Acoust., 83, 86 (1997).

19. P.S. Nikam, T.R. Mahale and M. Hasan, Acustica Acta Acoust., 84, 579 (1998).

20. P.S. Nikam, B.S. Jagdale, A.B. Sawant and M. Hasan, Acoust. Lett., 22, 199 (1999).

21. M. Geppert-Rybczynska, A. Heintz, J.K. Lehmann and A. Golus, J. Chem. Eng. Data, 55, 4114 (2010); https://doi.org/10.1021/je100315g.

22. M. Hasan, U.B. Kadam, A.P. Hiray and A.B. Sawant, J. Chem. Eng. Data, 51, 671 (2006); https://doi.org/10.1021/je0504459. 
23. U.B. Kadam, A.P. Hiray, A.B. Sawant and M. Hasan, J. Chem. Thermodyn., 38, 1675 (2006); https://doi.org/10.1016/j.jct.2006.03.010

24. M. Hasan, D.F. Shirude, A.P. Hiray, A.B. Sawant and U.B. Kadam, Fluid Phase Equilib., 252, 88 (2007); https://doi.org/10.1016/j.fluid.2007.01.001.

25. M. Hasan, D.F. Shirude, A.P. Hiray, U.B. Kadam and A.B. Sawant, J. Chem. Eng. Data, 51, 1922 (2006); https://doi.org/10.1021/je0602519.

26. M. Hasan, D.F. Shirude, A.P. Hiray, U.B. Kadam and A.B. Sawant, J. Mol. Liq., 135, 32 (2007); https://doi.org/10.1016/j.molliq.2006.10.012.

27. G.S. Manukonda, P. Venkatalakshami and K. Rambabu, Int. J. Phys. Res., 3, 5 (2013).

28. M. Gowrisankar, S. Sivarambabu, P. Venkateswarlu and K.S. Kumar, Bull. Korean Chem. Soc., 33, 1686 (2012); https://doi.org/10.5012/bkcs.2012.33.5.1686.

29. J. Timmermanns, Physico-Chemical Constants of Pure organic compounds; Elsevier publications; Amesterdam, 1950; Vol.1.

30. L. Venkatramana, K. Sreenivasulu, K. Sivakumar and K.D. Reddy, J. Therm. Anal. Calorim., 115, 1829 (2014); https://doi.org/10.1007/s10973-013-3473-9.

31. S. Singh, M. Aznar and N. Deenadayalu, J. Chem. Thermodyn., 57, 238 (2013); https://doi.org/10.1016/j.jct.2012.08.030.

32. S.K. Bindhani, G.K. Roy, Y.K. Mohanty and T.R. Kubendran, Russian J. Phys. Chem., 89, 1828 (2015); https://doi.org/10.1134/S0036024415100040.

33. S.J. Tangeda, S. Boodida and S. Nallani, J. Chem. Thermodyn., 38, 1438 (2006); https://doi.org/10.1016/j.jct.2006.01.009.

34. U.B. Kadam, A.P. Hiray, A.B. Sawant and M. Hasan, J. Chem. Eng. Data, 51, 60 (2006); https://doi.org/10.1021/je050169y.

35. T.M. Aminabhavi and V.B. Patil, J. Chem. Eng. Data, 43, 497 (1998); https://doi.org/10.1021/je980031y.

36. M.V. Prabhakara Rao and P.R. Naidu, J. Chem. Thermodyn., 8, 73 (1976); https://doi.org/10.1016/0021-9614(76)90153-1.

37. Sk.F. Babavali, D. Punyaseshudu, K. Narendra, Ch.S. Yesaswi and Ch. Srinivasu, J. Mol. Liq., 224, 47 (2016); https://doi.org/10.1016/j.molliq.2016.09.079.

38. C.M. Tridevi and V.A. Rana, Int. J. Sci. Res., 6, 48 (2015)

39. J.A. Riddick, W.B. Bunger and T.K. Sakano, Organic Solvents: Physical Properties and Methods of Purifications, Wiley Interscience, New York, edn 4 (1986).

40. A. Pal, R. Gaba and H. Kumar, J. Solution Chem., 40, 786 (2011); https://doi.org/10.1007/s10953-011-9688-0.

41. E. Vercher, A.V. Orchilles, P.J. Miguel and A. Martinez-Andreu, J. Chem. Eng. Data, 52, 1468 (2007); https://doi.org/10.1021/je7001804
42. M.S.Al-Tuwaim, H.A.E.K. Alkhaldi, S.A. Al-Jimaz and A.A. Mohammad, J. Chem. Thermodyn., 48, 39 (2012); https://doi.org/10.1016/j.jct.2011.12.002.

43. J.A. Riddick, W.B. Bunger and T.K. Sakano, Organic SolVents, Physical Properties and Methods of Purification, Techniques of Chemistry, Wiley-Interscience: New York, edn 4, vol. II (1986).

44. J. Peleteiro, D. González-Salgado, C.A. Cerdeirina, J.L. Valencia and L. Romani, Fluid Phase Equilib., 191, 83 (2001); https://doi.org/10.1016/S0378-3812(01)00614-8.

45. Z. Shan and A.-F.A. Asfour, Fluid Phase Equilib., 143, 253 (1998); https://doi.org/10.1016/S0378-3812(97)00267-7.

46. A.S. Al-Jimaz, J.A. Al-Kandary and A.-H.M. Abdul-Latif, Fluid Phase Equilib., 218, 247 (2004); https://doi.org/10.1016/j.fluid.2003.12.007.

47. P.S. Nikam, M.C. Jadhav and M. Hasan, J. Chem. Eng. Data, 40, 931 (1995); https://doi.org/10.1021/je00020a044.

48. B. Jacobson, J. Chem. Phys., 20, 927 (1952); https://doi.org/10.1063/1.1700615.

49. R. Nutsch-Kuhnkies, Acustica, 15, 383 (1965)

50. G.V. Rama Rao, A.V. Sarma and C. Rambabu, Indian J. Pure Appl. Phys., 42, 820 (2004)

51. K.V. Ramana Reddy, K. Rambabu, T. Devarajulu and A. Krishnaiah, Phys. Chem. Liq., 31, 9 (1996); https://doi.org/10.1080/00319109608029552.

52. R.S. Sah, B. Sinha and M.N. Roy, J. Chem. Eng. Data, 55, 4536 (2010); https://doi.org/10.1021/je100594u.

53. M. Hasan, A.P. Hiray, U.B. Kadam, D.F. Shirude, K.J. Kurhe and A.B. Sawant, J. Solution Chem., 40, 415 (2011); https://doi.org/10.1007/s10953-011-9657-7.

54. O. Kiyohara and G.C. Benson, J. Chem. Thermodyn., 11, 861 (1979); https://doi.org/10.1016/0021-9614(79)90067-3.

55. R.D. Rai, R.K. Shukla, A.K. Shukla and J.D. Pandey, J. Chem. Thermodyn., 21, 125 (1989); https://doi.org/10.1016/0021-9614(89)90122-5.

56. R.J. Fort and W.R. Moore, Trans. Faraday Soc., 61, 2102 (1965); https://doi.org/10.1039/tf9656102102.

57. K. Ramamoorthy and S. Alwan, Curr. Sci., 47, 334 (1978).

58. A.K. Nain, J. Mol. Liq., 140, 108 (2008); https://doi.org/10.1016/j.molliq.2008.01.016.

59. H. Wang, W. Liu and J. Huang, J. Chem. Thermodyn., 36, 743 (2004); https://doi.org/10.1016/j.jct.2004.04.004.

60. B. Hawrylak, K. Gracie and R. Palepu, J. Solution Chem., 27, 17 (1998); https://doi.org/10.1023/A:1022636511542.

61. P.K. Pandey, V.K. Pandey, A. Awasthi, A.K. Nain and A. Awasthi, Thermochim. Acta, 586, 58 (2014); https://doi.org/10.1016/j.tca.2014.03.038. 